\title{
Saneamento básico no estado do Rio de Janeiro: longo percurso rumo à regulação
}

\author{
Angela Moulin S. Penalva Santos ${ }^{1}$ \\ Juliana Santos ${ }^{2}$
}

\begin{abstract}
Resumo
Trata-se de um estudo geral ${ }^{3}$ do setor de saneamento básico após a Lei $n^{0} 11.445 / 07$ que regula o acesso dos servicos de abastecimento de água, esgotamento sanitário, coleta de resíduos sólidos e drenagem de águas pluviais urbanas. No decorrer do trabalho são discutidas algumas transformações trazidas com a Constituição de 1988 e a Lei dos Consórcios Públicos. Destaca-se na última sessão a apresentação de um panorama geral da oferta de serviços de saneamento básico no estado do Rio de Janeiro.
\end{abstract}

Palavras-chave: Saneamento Básico. Lei n 11.445/07; Regulação; Rio de Janeiro

\begin{abstract}
This work essays about how regulation impacts on sanitation service in the state of Rio de Janeiro. It is a general work of the sanitation sector since the foundation of Planasa until the present day and it is also about the "11.445/07 law" which regulates the access to the service of water supply, sewage, solid waste collection and urban stormwater drainage. In this work there is a discussion about the transformations brought by the 1988 Constitution and by the law of public consortia. The last session brings an overview of the provision of sanitation services in the State of Rio de Janeiro.
\end{abstract}

Keywords: Sanitation; 11.445/07 Law; Regulation; Rio de janeiro

\section{Introdução}

Dos setores de infraestrutura, o saneamento foi um dos últimos a se organizar e criar um marco regulatório. Esse atraso trouxe consequências graves para o setor. Com a extinção do PLANASA, o Plano Nacional de Saneamento, o Brasil passou a investir muito menos na formulação de políticas de âmbito nacional. Tentando se adaptar a este vazio institucional, estados e municípios passaram a elaborar e adotar suas próprias políticas de saneamento, na maioria das vezes de forma autônoma, sem qualquer integração com governo federal ou com setores de planejamento.

Depois de quase 20 anos de estagnação, um dos avanços mais importantes foi a aprovação em 2007 do marco legal do setor, estabelecendo as diretrizes nacionais para o saneamento básico. A lei define as ferramentas e as regras para o planejamento, a fiscalização, a prestação, a regulação dos serviços e possibilita o controle social sobre todas essas tarefas.

A obrigatoriedade da definição de um ente regulador autônomo para fiscalizar os serviços de saneamento básico foi um dos grandes progressos da Lei $\mathrm{n}^{\circ}$ 11.445/07 uma vez que a atividade regulatória era uma tarefa realizada pelas administrações locais ou realizada pelas próprias companhias estaduais de saneamento. A edição desse novo marco regulatório trouxe a expectativa de que a partir daí seriam estimulados princípios norteadores para o setor, como o planejamento, a regulação e o controle social.

O objetivo deste artigo é analisar a política de regulação no setor de saneamento básico no estado do Rio de Janeiro. O artigo é composto de 6 seções, além desta Introdução. Na

1 Angela Moulin S. Penalva Santos é professora associada da FCE/UERJ. angelapenalva@terra.com.br.

2 Juliana Santos é mestre em Economia pela FCE/UERJ. senninhabr@yahoo.com.br.

3 Este artigo tomou como referência a dissertação de mestrado de Juliana Santos, "Regulação do saneamento básico no Brasil: objetivos de política e as experiências nos municípios fluminenses", orientada por Angela Penalva Santos no Programa de PósGraduação em Economia da FCE/UERJ, em 2013. 
primeira, o objetivo é destacar a importância da regulação num setor sujeito à estrutura monopolística de mercado. A segunda é dedicada a sintetizar as origens do setor de saneamento básico. Na terceira seção, o objetivo é apontar os novos marcos legais que afetam o setor, casos das leis de consorciamento e da própria lei setorial. Na quarta seção apresentamos as diretrizes estabelecidas pela Lei 11.445/07, a lei que regula o saneamento básico no Brasil. A quinta seção apresenta os resultados do estudo de caso do estado do Rio de Janeiro, através de um panorama geral de como os serviços de saneamento são ofertados, seguida de uma análise sobre como o estado avançou neste setor seguindo as diretrizes do marco legal do saneamento básico. Na sexta e última seção são apresentados comentários gerais à guisa de conclusões.

\section{Saneamento: a importância da regulação de um setor sujeito à estrutura monopolista de mercado}

A regulação dos serviços públicos de infraestrutura é defendida em função da tendência de esses serviços serem oferecidos em condições monopolísticas. O monopólio natural é consequência da inviabilidade da prestação de serviços de uma mesma atividade por mais de um agente econômico, isto é, só é possível maximizar os resultados e alocar os recursos de maneira eficiente quando apenas um único agente econômico possui o direito de ofertar um bem ou serviço. Isso ocorre porque a realização de algumas atividades econômicas exige investimentos muito altos, o que acaba inviabilizando o estabelecimento de competitividade nas mesmas.

Este é o caso do saneamento, setor estruturado de forma vertical, dificultando a adoção de tarifas para diferentes fases da produção. A maioria das companhias de saneamento básico executa os serviços de produção, tratamento e distribuição de água, além da coleta e tratamento de esgoto, pois, caso a oferta desses serviços fosse realizada por empresas diferentes, os custos seriam maiores.

Nessas condições, qualquer esforço no sentido de estimular a ampliação da quantidade de produtores nessa indústria buscando incentivar a concorrência teria como resultado final a presença de uma ou mais plantas de escala sub-ótima. Vale ressaltar que, nesses casos, até as visões mais ortodoxas aceitam a regulação pública como uma ferramenta útil para coibir a prática de preços monopolísticos e para tentar mantê-los o mais próximo possível dos custos médios, além de outras tarefas (Possas; Ponde; Fagundes, 1997).

Segundo Madeira (2010), no saneamento básico, do ponto de vista da eficiência produtiva, a concorrência direta é inviável em qualquer estágio da produção e não é eficiente no sentido econômico e nem no sentido espacial. Não faria sentido, por exemplo, duas empresas atuarem no setor de água e esgoto competitivamente, com uma duplicação das redes de abastecimento e esgotamento. Seguindo esta concepção, dada à existência do monopólio natural, apenas um produtor conseguirá apresentar maior eficiência econômica.

\section{Origens da regulação do saneamento básico no Brasil}

Antes da implantação do Plano Nacional de Saneamento (PLANASA), os serviços de abastecimento de água e esgotamento sanitário eram executados pelos municípios, grande parte dos quais não apresentava capacidade técnica para adotar os planos elaborados pelo governo federal (Lobo, 2003). Tentando superar essa deficiência e buscando uma "racionalidade técnica" na utilização dos recursos financeiros, foi desenvolvido em 1969, e implantado em 1971, o Plano Nacional de Saneamento (Salles, 2008).

Este plano federal incentivou a criação de novas empresas estaduais de saneamento. Para tornar sustentável a atuação dessas companhias e garantir o sucesso do plano, ficava determinado que somente as companhias endossadas pelos estados e com participação em $50 \%$ dos FAEs (Fundos Estaduais de Água e Esgoto) seriam autorizadas a acessar os recursos do PLANASA (Lobo, 2003).

Em seu período de vigência, foram concebidas 27 companhias estaduais, que respondem 
ainda hoje pelo atendimento de mais de 3.700 municípios. A estratégia de concentrar a responsabilidade no nível estadual foi determinada por dois motivos principais: existiria uma maior facilidade para administrar os riscos através da concentração e também pelo estabelecimento de subsídios cruzados. A ideia era transferir a rentabilidade obtida pelo setor de saneamento nos municípios maiores para os municípios menores, cujos sistemas não eram considerados economicamente viáveis (Britto, 2009).

Entretanto, é importante destacar que a maior parte das concessões dos serviços de água e esgotamento sanitário era realizada sem a formalização de um contrato ou, na melhor das hipóteses, com contratos precários (Britto, 2009). Nos contratos de concessão não eram previstas ferramentas para fiscalizar a oferta e qualidade dos serviços de água e esgotamento sanitário e muito menos aspectos importantes de planejamento, criando assim um grande distanciamento entre as companhias estaduais, municípios e os consumidores (Araújo; Zveibil, 2009).

Para Wartchow (2009), o setor de saneamento passou por um difícil período na década de 1990 em virtude da falta de recursos financeiros (devido ao ajuste fiscal das contas públicas imposto em face do plano de estabilização monetária) e do veto do presidente da República ao Projeto de Lei da Câmara 199/94 (PLC 199). O Projeto de Lei que já tinha sido aprovado pelo Congresso Nacional procurava estabelecer uma política pública específica para o setor de saneamento, mas foi vetado integralmente, pois vinha na contramão dos objetivos do governo federal que pretendia privatizar o saneamento básico e outros serviços. Nunca é demais lembrar que, durante o Governo Fernando Henrique Cardoso (1995-2002), foram realizadas importantes reformas institucionais que redefiniram o papel do Estado num contexto em que o sucesso do Plano Real levou ao ajuste das contas públicas.

O que se observa entre as décadas de 1980 e 1990 é a fragmentação de recursos, diferentes órgãos e pastas do governo responsáveis pelo setor, inexistência de uma política nacional e coerente de saneamento, nível baixo de acesso aos serviços, inclusive nas regiões metropolitanas, e a falta de uma estrutura preocupada em coordenar as políticas nessa área. Com todos esses desafios, a política de saneamento passa a ser direcionada a determinados extratos sociais e a áreas urbanas específicas (Oliveira Filho, 2006).

Assim, este "vácuo institucional" possibilitou que a relação entre Companhias Estaduais de Saneamento Básico e os municípios continuassem seguindo a mesma organização estabelecida durante o PLANASA, mesmo décadas após a sua efetiva extinção, ocorrida em 1992 (Britto, 2009).

\section{Novos marcos regulatórios do saneamento básico}

Nesta seção vamos destacar duas importantes leis que afetam o setor de saneamento básico. A mais importante é Lei 11.445/07, que estabeleceu uma nova regulação setorial. Cabe, entretanto, destacar também a Lei 11.107/05 que regulou os consórcios públicos, uma vez que as características do saneamento básico tendem a estimular articulação interfederativa para viabilizar a oferta dos serviços. Esta última será objeto da sub-seção a seguir.

\section{A importância da lei dos consórcios na viabilidade da oferta dos serviços de saneamento}

Os municípios são os entes federativos responsáveis pelos serviços de saneamento. No entanto, a realidade dos 5.570 municípios no país é muito diferente no que se refere à densidade demográfica, cenário econômico, arrecadação de impostos, estrutura técnica e capacidade de gestão dos órgãos públicos. A maioria dos municípios não apresenta as condições necessárias para exercer a autonomia concedida pela Constituição de 1988. Este problema implica a enorme dependência que estes municípios têm em relação às transferências intergovernamentais. O Fundo de Participação Municipal é a fonte mais importante de recursos financeiros para mais de $80 \%$ dos municípios do Brasil.

Esse fato é um reflexo, em grande medida, da baixa capacidade de tributação da maioria dos municípios, pois os impostos municipais, tais como tributação da propriedade predial 
e territorial urbana, transmissão inter vivos de bens imóveis e os serviços de qualquer natureza, são essencialmente de caráter urbano, enquanto uma parcela significativa dos municípios brasileiros ainda possui suas economias baseadas nas atividades rurais. Desse modo, o processo de descentralização das políticas públicas levou a resultados muito diferentes, principalmente nos municípios menores que não apresentavam escala adequada para a execução dos serviços públicos (Santos, 2008).

Tentando superar essas dificuldades, a partir da década de 1990 cresceu bastante o número de associações entre dois ou mais municípios. Estes estabeleciam de forma voluntária o compromisso de solucionar conjuntamente uma determinada questão municipal que extrapolava os limites administrativos dos municípios (Britto, 2009). Isto permitia ganhos de escala na oferta de serviços públicos, pois, quanto maior a abrangência de atendimento da companhia que prestaria o serviço e quanto maior a população que teria acesso, menor seria o custo por residência e maior seria a possibilidade de cobrança de uma tarifa módica (Oliveira, 2004).

Entretanto, como os integrantes dos consórcios não possuíam uma personalidade jurídica, existia uma grande dificuldade para que assumissem compromissos e também para que usufruíssem de certos direitos individualmente (Britto, 2009). Embora fosse conferida aos consórcios públicos a natureza jurídica de cooperação associativa, não era uma prática muito comum atribuir personalidade jurídica a seus participantes, de forma que os consórcios continuavam sendo tratados como simples acordos. Assim, muitas vezes estes eram cancelados sem muitas dificuldades, tornando bastante instável a relação entre as partes envolvidas (Araujo; Zveibil, 2009).

Com a Lei $\mathrm{n}^{\circ} 11.107 / 05$, os consórcios públicos passaram a ter que assumir uma personalidade jurídica (ente de direito público ou de direito privado), o que parece ter resolvido o problema citado por Britto (2009). Atualmente, os consórcios são, necessariamente, pessoas jurídicas e, por isso, possuem direitos e obrigações (Oliveira; Nogueira, 2009).

Vale destacar também que, antes da Lei $\mathrm{n}^{\circ} 11.107 / 2005$, os consórcios só poderiam ocorrer entre pessoas públicas de natureza igual, ou seja, os arranjos eram horizontais (município com município, estado com estado, autarquia com autarquia) (Britto, 2009). A partir da Lei dos Consórcios, não só passaram a ser permitidos consórcios entre municípios não limítrofes e de estados diferentes, mas também consórcios compostos pelas três esferas do governo (Strelec e Fonseca, 2012).

Como já foi visto anteriormente uma parcela significativa dos serviços de saneamento básico é ofertada mediante contrato firmado entre um município e uma Companhia Estadual de Saneamento Básico (CESB). Contudo, uma parte relevante desses contratos não foi resultado de um ambiente competitivo (Cordeiro, 2009).

A Lei 11.107/2005 foi criada também para tentar solucionar esse problema. Para começar, a lei estabelece que esse tipo de contrato, sem a realização de uma licitação, que antes era definido como "contrato de concessão", passa a ser chamado de "contrato de programa" (Cordeiro, 2009). Ademais, apesar de não obrigar as associações constituídas anteriormente a criarem uma nova personalidade jurídica, o Tribunal de Contas passa a fiscalizar as movimentações contábeis, operacionais e de patrimônio, assim como a realização das receitas e despesas dessas associações, e a cobrar o cumprimento de todas as regras definidas para os consórcios formados depois da lei (Strelec; Fonseca, 2012).

De acordo com Cordeiro (2009) a Lei dos Consórcios Públicos estabelece que os serviços podem ser prestados apenas de três maneiras distintas:

1. o próprio titular executa diretamente o serviço de maneira centralizada, através de seus órgãos ou de maneira descentralizada (o serviço é realizado por autarquias municipais, empresas concessionárias, empresa pública municipal etc);

2. o titular fica responsável pela gestão dos serviços, mas concede a prestação de serviços a outrem por meio de um contrato somente após a realização de uma licitação;

3. os serviços públicos são realizados por intermédio de uma gestão associada.

Este último regime ocorre em um ambiente cooperativo entre os entes públicos participantes, através da organização de um consórcio público, e o serviço é prestado através de 
um contrato de programa. Para estes casos é dispensada a necessidade de uma licitação, desde que as duas partes do contrato pertençam à administração pública, ou seja, entes federados ou seus órgãos competentes.

Ademais, preocupando-se com as restrições financeiras dos consórcios, devido à falta de pagamento das contribuições mensais das "quotas-parte" por alguns dos participantes, a Lei $\mathrm{n}^{\circ} 11.107$ faz menção a um tipo específico de contrato chamado "contrato de rateio". $\mathrm{O}$ contrato de rateio é definido pelo decreto $\mathrm{n}^{\circ}$ 6.017/2007 como o "contrato por meio do qual os entes consorciados comprometem-se a fornecer recursos financeiros para a realização das despesas do consórcio público".

Como a inadimplência gerava uma série de dificuldades para a administração, entre elas, a incerteza quanto ao prosseguimento das atividades em andamento, a partir de 2005 ficou estabelecido que "o contrato de rateio será formalizado em cada exercício financeiro, com observância da legislação orçamentária e financeira do ente consorciado contratante e depende da previsão de recursos orçamentários que suportem o pagamento das obrigações contratadas" ( $\$ 1^{\circ}$ do art. 13 do Decreto $\left.\mathrm{n}^{\circ} 6.017 / 2007\right)$.

Dessa maneira, as leis 11.107/2005 e 11.445/2007 criaram dispositivos que ajudaram a enfraquecer a justificativa da existência de uma possível incapacidade institucional dos municípios para defender a conservação do "status quo" do setor de saneamento básico. Quando necessário, os municípios podem formar associações através de contrato de programa ou de consórcios públicos e contar inclusive com a participação do estado e do governo federal (Santos, 2009).

\section{Diretrizes estabelecidas pela Lei $\mathrm{n}^{\circ} \mathbf{1 1 . 4 4 5}$ para 0 saneamento básico}

Muitos dos contratos de concessão firmados na década de 1970, mesmo com os prazos de validade vencidos, não foram renegociados, e a prestação de serviços continuou sendo uma responsabilidade das companhias estaduais. Esses contratos eram muito autoritários, seguindo a tendência do período em questão, e não deixavam claro as obrigações das concessionárias e muito menos os direitos dos municípios enquanto titulares dos serviços de saneamento (Britto, 2009).

Um dos principais objetivos da Lei $\mathrm{n}^{\circ}$ 11.445/2007 é modificar esse cenário. Para isso, o marco regulatório estabelece diretrizes gerais para o saneamento básico. Define as ferramentas e as regras para o planejamento, a fiscalização, a prestação e a regulação dos serviços, tendo sido estabelecido o controle social sobre todas essas tarefas. Ademais, institui a formulação de Plano Municipal de Saneamento Básico como um documento obrigatório para o acesso aos recursos e apoio do governo federal, através de programas de financiamento, transferência de recursos, capacitação ou cooperação técnica (Moraes, 2009).

A agência reguladora, nos termos do artigo 22 da Lei $\mathrm{n}^{\circ} 11.445 / 07$, deve definir regras e padrões para garantir a prestação dos serviços e a satisfação dos usuários, fiscalizar o cumprimento das condições e metas estabelecidas nos contratos e planos de saneamento, prevenir e punir com multas e sanções o uso excessivo do poder econômico e determinar tarifas que permitam alcançar tanto o equilíbrio econômico e financeiro dos contratos como a modicidade tarifária (Probst, 2010).

A lei estabelece também como um dos fundamentos principais da regulação a fixação clara e objetiva dos direitos e obrigações de todas as partes envolvidas na prestação de serviços (poder público, prestador e usuário), cabendo ao regulador fiscalizar e assegurar o cumprimento dessas obrigações e garantir o respeito e acesso a esses direitos. O regulador deve ter autonomia decisória, independência administrativa, orçamentária e financeira, capacitação técnica e total transparência no seu trabalho (Marques Neto, 2005 apud Galvão Junior e Paganini, 2009).

Além disso, deve criar um ambiente em que existam previsibilidade e segurança jurídica. Ou seja, cabe ao ente regulador desenvolver mecanismos que evitem o comportamento discricionário dos agentes envolvidos. Esta função tem sido considerada fundamental para incentivar investimentos e garantir os contratos. Contudo, isto não quer dizer que a regula- 
ção tem que ser rígida e impossível de ser alterada ao longo do tempo. Na verdade, deve-se garantir transparência e antecipação de possíveis mudanças no setor regulado (Marques Neto, 2005 apud Galvão Junior e Paganini, 2009).

O marco regulatório criou grandes expectativas para o setor, entretanto, o que as experiências internacionais têm mostrado é que as mudanças estruturais no setor de saneamento básico são demoradas e complexas. De acordo com Galvão Junior (2009), tanto o Chile quanto a Inglaterra adotaram como "política a regionalização de pequenas empresas" e mais tarde a privatização, mas a consolidação de todas essas mudanças nestes dois países demorou mais de dez anos, o que sugere a existência de um longo caminho a percorrer.

\section{Funções de cada um dos entes federativos depois da Lei $n^{\circ} 11.445 / 07$}

A Lei n ${ }^{\circ} 11.445 / 07$, como já foi visto, trouxe muitas mudanças importantes. Esta seção estudará as funções de cada ente federativo à luz do marco regulatório do saneamento básico.

\section{Papel do governo federal}

De acordo com Heller (2009), entre as novas atribuições da União, destaca-se a obrigatoriedade da formulação de um Plano Nacional de Saneamento Básico (art. 52), o PLANSAB. O Plano deve considerar várias questões importantes, entre elas: a definição de metas nacionais e regionais necessárias para universalizar os serviços; a compatibilidade com as diversas políticas e programas do governo federal já em andamento; as formas de financiamento do plano e o acompanhamento periódico dos resultados de todas as ações adotadas.

Como destaca Heller (2009), levando em consideração o desenvolvimento do PLANSAB, existe uma contradição intrínseca relacionada ao planejamento da União. Ao mesmo tempo em que a legislação brasileira define o município como titular dos serviços de saneamento básico, reserva à União a competência de determinar objetivos e metas a serem alcançados pelo setor. É bem verdade que o principal financiador das políticas de saneamento é o governo federal. Grande parte dos investimentos no setor é garantida pela União através de recursos do Orçamento Geral da União (OGU), do Fundo de Garantia por Tempo de Serviço (FGTS) e do Fundo de Amparo ao Trabalhador (FAT). Assim, mesmo não tendo instrumentos legais para exigir que estados e municípios cumpram as metas, a União possui meios para influenciar a distribuição de recursos.

\section{Papel do governo estadual}

Para Montenegro (2009), a Lei n ${ }^{0} 11.445 / 07$ não estabelece claramente o papel dos estados. Primeiro, porque os estados não são os titulares dos serviços e depois porque caberia a estes as competências residuais.

O papel do estado também tem ficado em segundo plano em virtude da predominância que as companhias estaduais dispõem na esfera das administrações estaduais. Tais companhias possuem grande influência política e, na maioria das vezes, não se submetem à Secretaria de Estado a que deveriam responder. Esta configuração traz diversas consequências para o saneamento, como a tendência à falta de investimentos nas localidades em que as companhias estaduais não são responsáveis pelos serviços de abastecimento de água e esgotamento sanitário e a pouca atenção dispensada aos serviços de manejo de resíduos sólidos e de águas pluviais, já que as companhias não atuam nestas duas modalidades (Montenegro, 2007).

Apesar desses problemas, segundo Oliveira Filho (2009), existem formas de o governo estadual intervir na gestão dos serviços de saneamento. Isso pode acontecer através de convênios com os municípios (Lei do Consórcio Público) e até mesmo incentivando à regionalização. Assim, o Estado tem um papel fundamental na busca pela universalização dos serviços, ao prestar os serviços via companhias estaduais ou apoiar os municípios que não são atendidos por elas (Oliveira Filho, 2009).

Já as companhias estaduais, com a edição das recentes Leis do Saneamento e do Consorcio Público, devem passar por reformas institucionais significativas. A partir das recentes leis, precisam prestar contas aos municípios e à população em geral, assegurar transparência em suas decisões, garantir a eficiência na prestação de serviços e cumprir metas previamente estabelecidas, buscando a universalização do acesso ao saneamento (Oliveira Filho, 2009). 


\section{Papel dos municípios}

Os municípios precisam cumprir uma série de determinações previstas pela Lei n ${ }^{\circ}$ 11445/07. Uma das mais importantes é a elaboração de um plano que pode ser realizada pelo próprio município ou através de um Consórcio Público do qual faça parte. O marco regulatório do saneamento básico vincula a renovação ou a validade de novos contratos à edição desse plano, à elaboração de uma legislação municipal de regulação e à escolha de um órgão regulador (Bastos, 2009).

Cabe aos municípios escolher a maneira como o serviço de saneamento será prestado (de forma direta ou mediante concessão) e estabelecer sua possível participação; definir níveis de comparação da quantidade, regularidade e qualidade da água distribuída; decidir a que ente caberá a fiscalização e a regulação do setor; definir de forma clara os direitos e os deveres dos consumidores; criar meios e instrumentos de participação e controle social; criar um banco de dados sobre os serviços; definir as situações em que haja a necessidade do município intervir ou até mesmo suspender o contrato em vigor; elaborar um plano de saneamento básico considerando sua viabilidade técnica, financeira e econômica; definir como será realizada a cobrança dos serviços e a composição das tarifas; determinar as políticas de subsídios, entre outras atribuições (INSTITUTO TRATA BRASIL, 2010).

\section{A regulação do setor de saneamento básico: o caso do estado do Rio de Janeiro}

Conforme aponta Probst (2010:1), existem várias maneiras de regular os serviços:

1. municípios que delegaram o exercício da atividade de regulação à agência estadual somente no que toca ao abastecimento de água e esgotamento sanitário;

2. municípios que delegaram o exercício da atividade de regulação à agência estadual de todas as atividades do saneamento básico;

3. municípios que criaram agência de regulação no âmbito municipal; e

4. municípios não abrangidos por nenhuma atividade de regulação, decorrente da não delegação ou inexistência de entidade regulatória de abrangência estadual ou municipal.

Acompanhando a abordagem deste autor, esta seção tentará construir um panorama geral de como se dá a oferta dos serviços de saneamento nos municípios fluminenses e buscará estudar as medidas tomadas para a adaptação do estado do Rio de Janeiro à Lei 11.445/07 e à Lei dos Consórcios Públicos.

Em uma primeira análise é possível notar, por exemplo, que, apesar da prestação regionalizada de serviços de saneamento ser apontada como um avanço, possibilitando a superação de distorções no modelo federativo do Brasil, o estado do Rio de Janeiro não possui uma política de corte regional. Não conta, ademais, com uma política estadual de saneamento básico, que poderia contribuir de forma significativa para elaborar políticas de planejamento de abrangência regional (considerando as especificidades de cada município) bem como adequação de programas, estabelecimento de prazos e construção de indicadores para a esfera estadual (ABAR, 2013).

Contudo, a aprovação de uma política estadual de saneamento, de acordo com ABAR (2013), é um dos grandes desafios do setor. Os altos custos de transação para chegar a um consenso político de uma lei de abrangência estadual e o risco de divergências judiciais quanto às competências dos entes federativos, além da grande probabilidade da lei aprovada ser considerada inconstitucional, são justificativas que dificultam o avanço nesse ponto.

Assim, este estudo começará analisando a Companhia Estadual de Água e Esgoto do Rio de Janeiro (CEDAE), a segunda maior companhia de saneamento básico do Brasil, criada ainda durante a vigência do PLANASA, nos anos 1970.

Para facilitar a visualização da abrangência da CEDAE segue a Figura 1. Observando o 
mapa, não é difícil concluir que o método de gestão de serviços adotado durante a década de 1970, em que os municípios delegavam os serviços de saneamento às companhias estaduais, não sofreu grandes alterações.

Figura 1: Área de atuação da CEDAE no estado do Rio de Janeiro

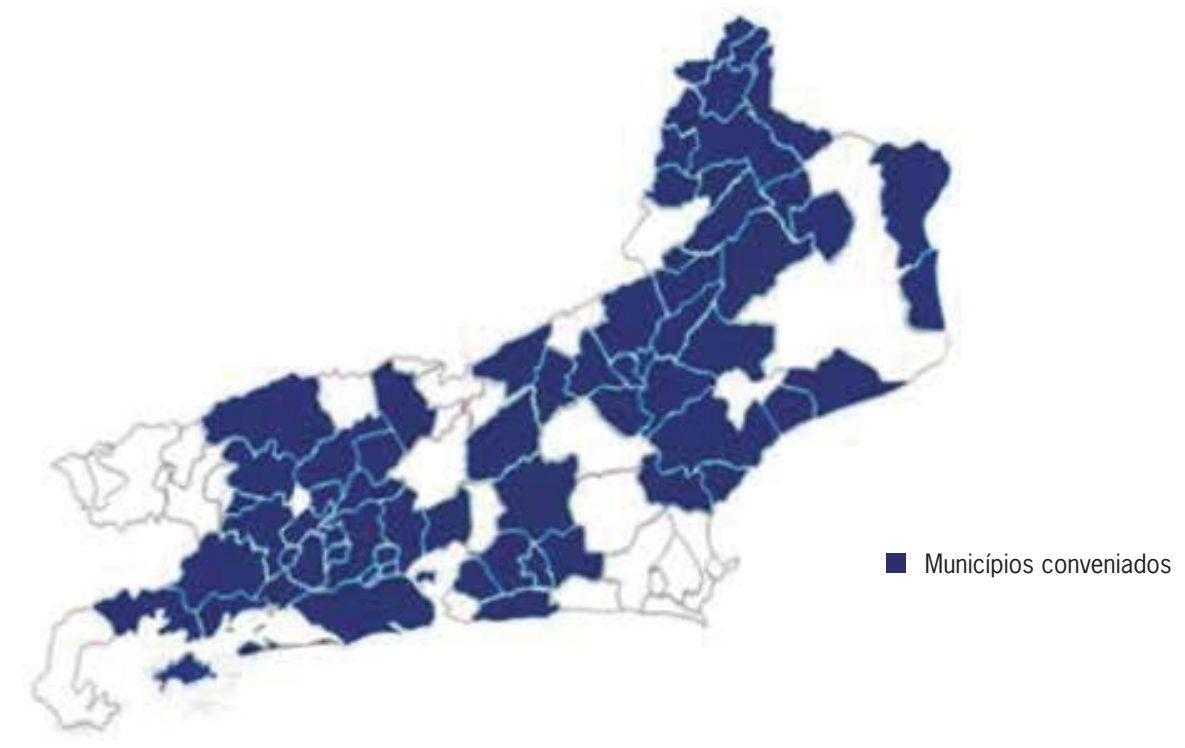

Fonte: CEDAE (2012)

De acordo com CEDAE (2012), a companhia continua prestando serviços de água e esgoto para os municípios da Tabela 1, mesmo com os contratos da concessão vencidos e em processo de negociação para renovação.

Tabela 1: Municípios com contratos da concessão à Cedae vencidos e com renovação ainda em negociação

\begin{tabular}{ll}
\hline Municipios & Serviços \\
\hline Angra dos Reis* & Água \\
Cachoeiras de Macacu** & Água \\
\hline Cambuci & Água \\
Mangaratiba & Água e esgoto \\
\hline Miracema & Água \\
Porciúncula & Água e esgoto \\
Quissamã & Água e esgoto \\
São João da Barra & Água e esgoto \\
\hline Teresópolis & Água e esgoto \\
\hline
\end{tabular}

* No município de Angra dos Reis, a CEDAE opera parcialmente no sistema de água, deixando toda par te do sistema de esgoto para a SAAE (Serviço Autônomo de Água e de Esgoto).

** Em Cachoeira do Macacu, a CEDAE e a Autarquia Municipal de Águas e Esgotos (AMAE) realizam os serviços de água e esgotamento no município.

Fonte: Cedae (2012)

Como foi visto anteriormente, hoje o saneamento básico conta com uma legislação que diminui o comportamento discricionário dos agentes envolvidos, ao estabelecer determinadas normas para os novos contratos, aumentando assim a possibilidade da participação da iniciativa privada no setor. Isso acabou criando oportunidade para os municípios que estavam insatisfeitos com a prestação de serviços da CEDAE. 
O caso da Região dos Lagos é um bom exemplo da parceria com investidores privados. Os municípios apresentavam graves problemas de disponibilidade de água e baixíssimas porcentagens de domicílios conectados à rede geral de esgotamento sanitário ou pluvial, pois, segundo a CEDAE, esta região dava muitos prejuízos. Isso trouxe muitos problemas não só para os moradores, mas para as diversas atividades econômicas locais, em especial para as relacionadas ao turismo (Vargas; Lima, 2004). Tentando reverter esta situação, em 1998, os municípios de Armação de Búzios, Cabo Frio, Iguaba Grande, São Pedro da Aldeia e Arraial do Cabo, estimulados inclusive pela CEDAE (tamanho era o desinteresse da companhia pela região), formaram um consórcio e delegaram os serviços de água e esgoto à concessionária Prolagos durante 25 anos (Pires do Rio; Sales, 2004). De acordo com Agenersa, no caso do município de Arraial do Cabo, o contrato era apenas para a distribuição de água.

Algo parecido aconteceu também em Nova Friburgo. Neste município, em 1999, foi criada a CAENF (Companhia de Água e Esgoto de Nova Friburgo), através de um consórcio constituído por investidores brasileiros e estrangeiros, encabeçado pela Earth Tech Brasil (que pertence a Tyco Engenharia, empresa portuguesa), que conquistou o direito de explorar os serviços de saneamento básico por 25 anos (Pires do Rio; Sales, 2004).

Vale destacar que a decisão de mudança de prestadora de serviços de saneamento básico, que por lei cabe aos titulares dos serviços, muitas vezes não é aceita de maneira "amigável" pelas companhias estaduais de saneamento básico. Segundo Cruz e Ramos (2012), a atual configuração do setor leva a alguns conflitos de interesse, dado que os estados detentores de CESBs não concordam com o desligamento de alguns municípios que apresentam uma significativa lucratividade e almejam um Sistema de Abastecimento de Água e de Coleta de Esgoto autônomo municipal ou a parceria com o setor privado. $\mathrm{O}$ caso mais antigo de Niterói e os recentes de Paraty e Santo Antônio de Pádua podem exemplificar bem essa situação.

Em Niterói, a motivação da transferência à iniciativa privada foi a falta de investimentos da Companhia Estadual de Saneamento na parte do município ocupada por bairros populares e de classe média que não contavam sequer com redes de abastecimento de água e redes de esgotamento sanitário. Desse modo, em 1997, depois de um contrato firmado com a Prefeitura, contrariando a vontade da CEDAE e do governo estadual, a prestação dos serviços de água e esgotamento sanitário foi concedida por três décadas a Cia. Águas de Niterói, constituída por um consórcio de empresas nacionais de engenharia e construção. Isso levou a uma longa discussão na Justiça com a companhia estadual, retardando por dois anos a delegação dos serviços de saneamento ao consórcio Cia. Águas de Niterói (Vargas; Lima, 2004).

Paraty, depois de uma disputa judicial, conseguiu a aprovação da Assembleia Legislativa do Rio do Projeto de Lei 1.683/12, em 2013, que permite a municipalização dos serviços de abastecimento de água e esgotamento sanitário. A maioria das reclamações do município estava relacionada ao grande descaso da CEDAE, principalmente com os serviços de esgotamento sanitário.

Utilizando os dados contidos no Banco de Dados do Projeto UERJ/Sefaz-RJ, na seção de saneamento, e na seção de demografia, é possível constatar este problema. Em 2010 apenas $13 \%$ dos domicílios particulares permanentes em Paraty estavam conectados a uma rede geral de esgoto ou pluvial (Porto, 2013). Em Santo Antônio de Pádua, a CEDAE (2012) declara que os serviços de abastecimento de água e esgotamento sanitário estão suspensos em razão da existência de uma ordem judicial ainda em andamento. Não foi possível encontrar mais informações sobre o desfecho dessa questão.

\section{Rio de Janeiro não se submete ao marco legal do saneamento básico}

Após a análise de alguns aspectos importantes do marco regulatório do saneamento básico, é possível observar a falta de comprometimento do estado do Rio de Janeiro com as suas diretrizes.

Apesar de a Lei $\mathrm{n}^{\circ} 11.445 / 07$, como foi apontado anteriormente, determinar que todos os operadores dos serviços sejam submetidos a uma regulação e normatização, a Agência Reguladora de Energia e Saneamento Básico do estado do Rio (Agenersa) surpreendente- 
mente responde apenas pela regulação, controle, fiscalização das atividades de abastecimento de água e esgotamento sanitário e dos contratos dos consórcios Prolagos e Águas de Juturnaíba.

Em relação à CEDAE, que presta serviços de abastecimento de água e esgoto para maior parte dos municípios do Rio de Janeiro atendendo a mais de 10 milhões de pessoas, ou seja, cerca de $80 \%$ da população fluminense (CEDAE, 2012), está previsto pelo Decreto Estadual $\mathrm{n}^{\circ} 43.982$, de 11/12/2012 que esta empresa só passará a ser submetida à regulação da Agenersa em 2015, 8 anos depois da entrada em vigor do marco regulatório.

Sendo assim, tem-se o seguinte quadro no estado do Rio de Janeiro: dos 92 municípios, apenas Araruama, Silva Jardim, Saquarema (Águas de Juturnaíba) e Armação de Búzios, Arraial do Cabo, Cabo Frio, Iguaba Grande, São Pedro da Aldeia (Prolagos) estão sendo submetidos a uma regulação. Isso significa que apenas cerca de 9\% dos municípios do estado têm os serviços de água e esgotamento sanitário regulados.

Para ilustrar a incipiência da regulação no Rio de Janeiro e que esses dados revelam uma abrangência quase irrelevante da agência reguladora no estado, vale comparar com área de atuação de outras agências estaduais do Brasil. Na Bahia 87,3\%, em Minas Gerais 73,6\% e em São Paulo 41,6\% dos municípios são submetidos à regulação.

Tabela 2: Abrangência de algumas agências reguladoras estaduais

\begin{tabular}{lcc}
\hline Agência reguladora de saneamento básico & $\begin{array}{c}\text { Quantidade } \\
\text { de municípios } \\
\text { regulados }\end{array}$ & $\begin{array}{c}\text { Porcentagem } \\
\text { de municipios } \\
\text { regulados (\%) }\end{array}$ \\
\hline $\begin{array}{l}\text { Agenersa (Agência Reguladora de Energia e Saneamento Básico do } \\
\text { estado do Rio de Janeiro) }\end{array}$ & 8 & 8,7 \\
$\begin{array}{l}\text { Arsae (Agência Reguladora de Serviços de Abastecimento de Água e } \\
\text { de Esgotamento Sanitário do Estado de Minas Gerais) }\end{array}$ & 628 & 73,6 \\
\hline $\begin{array}{l}\text { Agersa-BA (Agência Reguladora de Saneamento do Estado da Bahia) } \\
\text { ARSESP (Agência Reguladora de Saneamento e Energia do Estado de } \\
\text { São Paulo) }\end{array}$ & 364 & 87,3 \\
\hline
\end{tabular}

Fonte: ABAR (2013)

Como ressalta Hohmann (2012), após a Lei $\mathrm{n}^{0} 11.445 / 07$, o estado passaria a ter uma nova função, deixando de ser o prestador direto dos serviços de saneamento para atuar como fiscalizador e regulador dessas atividades. Entretanto, o cenário no estado do Rio de Janeiro é muito diferente. Não só a escolha dos municípios de não renovar o contrato com a Companhia Estadual de Saneamento Básico leva a conflitos judiciais como a atuação da agência reguladora estadual é de mínima abrangência.

Outro problema sério é o atraso na elaboração dos planos municipais de saneamento. $\mathrm{O}$ segundo prazo para a entrega dos planos encerrou no final de 2013 (o primeiro ia até 2010 e foi prorrogado) e poucos municípios conseguiram finalizar e entregar os planos a tempo. Agora o prazo foi estendido para 2015. É interessante lembrar que a Lei $n^{\circ} 11.445 / 2007$ determina que o município que não entregar o plano fica proibido de receber transferências da União na área de serviços e infraestrutura de saneamento básico, criando dificuldades para investimentos no setor (Bugalho, 2013).

No estado do Rio de Janeiro a SEA (Secretaria de Estado do Ambiente) estaria apoiando a elaboração de 72 planos municipais de saneamento básico. O que preocupa, na verdade, é que, segundo informações da própria página do governo federal ${ }^{4}$ (consultada no dia 12/06/2014), estariam prontos os planos municipais apenas de cinco municípios: Magé, Tanguá, Cachoeiras do Macacu e Guapimirim, Rio Bonito, e no processo de finalização: Araruama, Armação de Búzios, Arraial do Cabo, Cabo Frio, Iguaba Grande, São Pedro da Aldeia, Saquarema e Silva Jardim. Isto significa que, dos 72 municípios que Secretária de Estado do Ambiente está auxiliando, 67 municípios ainda não estão em fase de conclu-

4 Mais informações no endereço <http://www.rj.gov.br/web/sea/exibeconteudo?article-id=1461705>. 
são. De acordo com a ABAR (2013), encontram-se no grupo dos municípios sem um plano municipal de saneamento básico os oito regulados pela Agenersa. É importante destacar que esse não é um problema apenas do estado do Rio de Janeiro. O prazo para entrega dos planos municipais de saneamento básico tem sido prorrogado constantemente. Antes era para o final de 2013, agora é 2015. Isso porque mais de $90 \%$ dos municípios brasileiros não tiveram condições de cumprir o prazo anterior.

Além disso, se o marco regulatório veta termos de parceria ou outros instrumentos de condição precária, o que dizer, por exemplo, dos serviços que continuam a ser prestados pela CEDAE mesmo com os contratos vencidos, nos municípios de Angra dos Reis, Cachoeiras do Macacu, Cambuci, Mangaratiba, Miracema, Porciúncula, Quissamã, São João da Barra e Teresópolis?

Outro indicativo de descumprimento com a norma que regula o saneamento básico refere-se ao valor das tarifas. Conforme declara o consultor do Ministério das Cidades, Ribeiro (2013), os ajustes das tarifas aplicados em contratos fechados após a Lei $n^{0} 11.445 / 07$ são questionáveis porque a lei determina que os reajustes tarifários só podem ser realizados com o acompanhamento de um agente regulador. Destaca ainda que o que está acontecendo no estado do Rio de Janeiro pode ser considerado uma "improbidade administrativa". Não são poucos os contratos firmados após a lei, pela CEDAE, por exemplo. Dos 55 municípios (desconsiderando os nove com contrato vencido), 43 contratos foram renovados depois de 2007. Ou seja, $78 \%$ dos contratos da Companhia foram firmados ou renovados após a Lei do Saneamento. Em 2000, o governador do estado do Rio de Janeiro através do Decreto 25.997/00 delegou ao presidente da CEDAE a competência de decidir quando deve ter que elevar as tarifas e qual o valor desse aumento, e aparentemente esse poder não foi revogado.

Seguindo esse contexto, para mostrar a importância das agências reguladoras, vale destacar que as concessionárias Águas de Juturnaíba e Prolagos já foram multadas algumas vezes pela Agenersa por tentarem compensar os altos investimentos com aumentos relevantes nas tarifas, por não fornecerem água a determinadas localidades e muitos outros problemas (Vargas; Lima, 2004).

E como se não bastassem apenas 8 municípios regulados no estado do Rio de Janeiro, a própria Agenersa está sendo autuada pelo Ministério Público, juntamente com a Prolagos e Águas de Juturnaíba e o estado do Rio de Janeiro, por permitir a cobrança desde 2004 de uma tarifa de esgoto que não vinha sendo discriminada nos boletos de cobrança. Os usuários não eram informados que pagavam por um serviço que em muitos locais nem existia. Entre 2004 e 2013, as duas concessionárias privadas e reguladas pela Agenersa embutiram a cobrança da tarifa de esgotamento nas contas de e água (SILVA JARDIM.COM, 2013).

\section{Conclusões}

A principal conclusão do estudo é que as políticas institucionais no Rio de Janeiro ainda não se ajustaram aos princípios estabelecidos no novo marco regulatório do saneamento básico, não obstante tratar-se de setor cujas características organizacionais se aproximem das condições que definem um monopólio natural.

A experiência brasileira mostra que, durante quase 20 anos, desde o fim do PLANASA, o setor passou por um longo período de estagnação. Esta situação só começou a ser revertida após a entrada em vigor de um marco regulatório para o setor.

A Lei do Saneamento criou um ambiente institucional estável para promover a eficiência, a qualidade e a universalidade dos serviços, visando a atrair investimentos privados e expandir a concorrência pelos contratos de concessão. Apesar disso, percebe-se que o estado do Rio de Janeiro não toma medidas para incentivar a prestação regionalizada, a gestão associada ou a participação da iniciativa privada na prestação dos serviços de abastecimento de água e esgotamento sanitário. A configuração do setor ainda é muito semelhante à herança deixada pelo PLANASA. Observa-se que as companhias estaduais possuem ainda um grande poder político e está havendo uma resistência para modificar este cenário que já existe desde a década de 1970.

A Companhia Estadual de Abastecimento de Água e Esgoto do Rio de Janeiro continua responsável pelo abastecimento de água da maioria dos municípios fluminenses e, somente 
a partir de 2015, começará a ser regulada pela Agenersa. Assim, enquanto não é fiscalizada, a segunda maior companhia de saneamento do país não tem seu desempenho acompanhado e pode ajustar livremente suas tarifas. A falta de regulação permite que existam municípios como São Francisco do Itabapoana que tem apenas 1\% de seus domicílios ligados à rede geral de esgotamento sanitário.

Não bastasse o número quase irrelevante de municípios submetidos à regulação, vale destacar que o papel da Agenersa algumas vezes também não vem sendo cumprido de acordo com as diretrizes do marco regulatório do setor. A $2^{\text {a }}$ Promotoria de Justiça de Tutela Coletiva de Araruama ajuizou duas ações na área civil pública envolvendo a agência reguladora por permitir que ambas cobrassem desde 2004 a tarifa de esgotamento sanitário "disfarçada" em elevação da tarifa de água.

Assim, o que mais chama a atenção no fim da pesquisa é a desconsideração do estado do Rio de Janeiro com as diretrizes da legislação em vigor. Acreditamos que, se a CEDAE fosse submetida à regulação como estabelece a Lei 11.445/07, haveria uma expansão e melhoria significativa dos serviços ofertados.

Este resultado deve ser ainda mais lamentado quando se considera o impacto negativo que a insuficiência na cobertura dos serviços de saneamento causa nas condições de vida da população. Num contexto marcado pelos avanços nas políticas sociais, que resgataram um contingente não inferior a 30 milhões de brasileiros da condição de pobreza, a falta de saneamento deveria ser objeto não apenas de esforços no sentido de cumprir o que a lei já prevê, mas também em explorar as possibilidades de ampliar a oferta do acesso ao saneamento por meio de parcerias institucionais que a Lei dos Consórcios Públicos busca estimular. É longo, portanto, o caminho que o estado do Rio de Janeiro ainda deve percorrer rumo à regulação do saneamento básico.

\section{Referências bibliográficas}

ARAÚJO, Marcos Paulo Marques; ZVEIBIL, Victor Zular. A relação titular-prestador nos serviços na contratação dos serviços de saneamento básico. In: CORDEIRO, Berenice de Souza (Org.). Lei Nacional de Saneamento Básico: Perspectivas para as políticas e gestão dos serviços públicos. Brasília: Ministério das Cidades, 2009. vol. 3, p.467-486.

ASSOCIAC̣ÃO BRASILEIRA DAS AGÊNCIAS DE REGULAC̣ÃO (ABAR). Saneamento básico: Regulação 2013.

Fortaleza: Expressão Gráfica e Editora, 2013. 94 p

BASTOS, Rafael Kopschitz Xavier. Oportunidades e desafios para os prestadores municipais de serviços de saneamento básico. In: CORDEIRO, Berenice de Souza. (Org.). Prestação dos serviços públicos de saneamento básico. Lei Nacional de Saneamento Básico: perspectivas para as políticas e gestão dos serviços públicos. Brasília: Ministério das Cidades, vol. 3, p.559-570, 2009.

BRITTO, Ana Lúcia (Org.). Panorama do saneamento básico no Brasil: Avaliação político-institucional do setor de saneamento básico. Brasilia: Ministério das Cidades, 2011. 533p.

BRITTO, Ana Lucia. Gestão regionalizada de servicos de saneamento. In: CORDEIRO, Berenice de Souza (Org.) Lei Nacional de Saneamento Básico: Perspectivas para as políticas e gestão dos serviços públicos. Brasília: Ministério das Cidades, 2009. vol. 1, p.129-146.

BUGALHO, Gustavo Russignoli. Plano Municipal de Saneamento Básico: 0 tempo se esgota e as consequências batem à porta. Abcon, 2013. Disponivel em: <http://www.abcon.com.br/impr_01. php?catld=14\&contld=862>. Acesso: 29 jul. $201 \overline{3}$.

CEDAE. Relatório da administração e demonstrações financeiras 2012. Rio de Janeiro, 2012. 118p.
CORDEIRO, Berenice de Souza. Capacitação. In: CORDEIRO, Berenice de Souza (Org.). Lei Nacional de Saneamento Básico: Perspectivas para as políticas e gestão dos serviços públicos. Brasília: Ministério das Cidades, 2009. vol. 3, p.600-612.

CRUZ, Karlos Eduardo Arcanjo; RAMOS, Francisco de Souza. Eficiência na gestão do saneamento básico e seus impactos sobre a promoção da saúde: uma aplicação da análise envoltória de dados - DEA. In: Encontro Regional de Economia (ANPEC-Nordeste), $n^{\circ} 17$, Fortaleza, 2012. 18p.

GALVÃO JUNIOR, Alceu de Castro. Desafios para a regulacão subnacional do saneamento básico no Brasil. İn: PROENCCA, Jadir Dias et al. Desafios da regulação no Brasil. Brasília: Enap, 2009. Cap. 4, p.275-309.

PAGANINI, Wanderley da Silva. Aspectos conceituais da regulação dos serviços. Eng Sanit Ambient, vol. 14, n.1, p.79-88, Fortaleza, jan. 2009.

HELLER, Leo. 0 papel da União na política de saneamento básico: entre 0 que se deve e o que se pode esperar. In: CORDEIRO, Berenice de Souza (Org.). Lei Nacional de Saneamento Básico: Perspectivas para as políticas e a gestão dos serviços públicos. Brasília: Ministério das Cidades, 2009. vol. 1, p.87-99.

HOHMANN, Ana Carolina C. Regulação e saneamento na Lei Federal $n^{\circ} \mathbf{1 1 . 4 4 5 / 0 7}$. Revista Jurídica da Procuradoria Geral do Estado do Paraná, Curitiba, n. 3, p. 211-244, 2012.

INSTITUTO TRATA BRASIL (Org.). Benefícios econômicos da expansão do saneamento brasileiro. São Paulo:

Fundacão Getúlio Vargas - IBRE (Instituto Brasileiro de Economia), 2010. 32p.

LOBO, Luiz. Saneamento básico: em busca da universalização. Brasília: Ed. do Autor, 2003. 228p. 
MADEIRA, Rodrigo Ferreira. 0 setor de saneamento básico no Brasil e as implicações do marco

regulatório para a universalização. Revista do BNDES, Rio de Janeiro, n. 33, p.123-154, 2010.

MONTENEGRO, Marcos Helano Fernandes. Potencialidade da regionalização da gestão dos serviços públicos de saneamento básico. In: CORDEIRO, Berenice de Souza (Org.). Lei Nacional de Saneamento Básico: perspectivas para as políticas e gestão dos serviços públicos. Brasília: Ministério das Cidades, 2009. vol. 1, p.147-162.

MONTENEGRO, Marcos Helano Fernandes. Considerações sobre a regulação e a regionalização dos serviços públicos de saneamento básico no estado da Bahia. Brasília, 2007. 30p.

MORAES, Luiz Roberto Santos. Política e Plano Municipal de Saneamento Básico: aportes conceituais e metodológicos. In: CORDEIRO, Berenice de Souza (Org.). Lei Nacional de Saneamento Básico: Perspectivas para as políticas e gestão dos serviços públicos. Brasília, 2009. vol. 1, p.33-53.

OLIVEIRA FILHO, Abelardo de. Institucionalização e desafios da política nacional de saneamento: um balanço prévio. 2006. Disponível em: <http://www.assemae. org.br/ artigoabelardo.pdf>. Acesso em: 13 ago. 2013.

. O papel dos estados e as perspectivas das companhias estaduais de saneamento básico frente ao novo contexto institucional. In: CORDEIRO, Berenice de Souza (Org.). Lei Nacional de Saneamento Básico: perspectivas para as políticas e gestão dos servicos públicos. Brasília: Ministério das Cidades, 2009. vol. 3, p.543-556.

OLIVEIRA, Anderson Luís Silva de. Saneamento básico no Brasil: limites e possibilidades de atuação do setor privado. Dissertação (Mestrado) - Universidade Federal da Bahia, Salvador, 2004. $91 \mathrm{f}$

OLIVEIRA, Flávia de Paiva Medeiros; NOGUEIRA, Carla Felinto de. A importância dos consórcios públicos intermunicipais para a defesa do meio ambiente. Direito e Liberdade, vol. 6, n. 2, p.77-86, Natal, 2009.

PIRES DO RIO, Gisela Aquino Pires do; SALES, Alba Valéria de Souza. Os serviços de água e esgoto no estado do rio de janeiro: regulação e privatização. Geografia, n. 12, p.67-86, Rio de Janeiro, 2004

PORTO, Fernanda. Autorizado convênio para saneamento em Paraty. Disponível em: <http://www.alerj.rj.gov.br/ common/noticia_corpo.asp?num $=44061>$. Acesso em: 26 set. 2013 .
POSSAS, Mario Luiz; PONDE, João Luiz; FAGUNDES, Jorge. Regulação da concorrência nos setores de infraestrutura no Brasil: elementos para um quadro conceitual. Brasília: Ipea, 1997. 40p.

PROBST, Marcos Fey. Agência intermunicipal de regulação do saneamento. Jus Navigandi, n. 2504 , Teresina, mai. 2010. Disponível em: <http://jus.com.br/ revista/texto/14816>. Acesso em: 17/08/2012.

RIBEIRO, Wladimir Antônio. CEDAE, uma caixa-preta sem controle. Jornal $O$ Globo. Entrevista concedida em 31/07/2013 a ALENCAR, Emanuel; SCHMIDT, Selma. Rio de Janeiro. Disponivel em: <http://oglobo.globo.com/rio/ cedae-uma-caixa-preta-sem-controle-9292117>. Acesso em: 21 ago. 2013

SALLES, Maria José. Política Nacional de Saneamento: Percorrendo caminhos em busca da universalização. Tese (Doutorado) - Escola Nacional de Saúde Pública Fundação Oswaldo Cruz, Rio de Janeiro, 2008. 185 f.

SANTOS, Ângela Moulin Penalva. Municipio, descentralização e território. Rio de Janeiro: Editora Forense, 2008. p.184-240.

SANTOS, Johnny Ferreira Dos. 0 saneamento como instrumento de promoção da saúde. In: CORDEIRO, Berenice de Souza (Org.). Lei Nacional de Saneamento Básico: Perspectivas para as políticas e gestão dos serviços públicos. Brasília: Ministério das Cidades, 2009. vol.2, p.357-366.

SILVA JARDIM.COM (Rio de Janeiro). Ministério Público enquadra Águas de Juturnaíba e Prolagos. Disponível em: <http://silvajardim.com/mp-enquadra-aguas-dejuturnaiba-e-prolagos/>. Acesso em: 15 out. 2013.

STRELEC, Thamara; FONSECA, Francisco. Alcances e limites da Lei dos Consórcios Públicos: um balanço da experiência consorciada no estado de São Paulo. Cadernos Adenauer, São Paulo, vol.4, p.1-15, 2011.

VARGAS, Marcelo Coutinho; LIMA, Roberval Francisco De. Concessões privadas de saneamento no Brasil: bom negócio para quem?. Ambiente \& Sociedade, v. 7, n. 2 , p.68-93, Campinas, dez. 2004.

WARTCHOW, Dieter. Servicos de abastecimento de água e de esgotamento sanitário. In: CORDEIRO, Berenice de Souza (Org.). Lei Nacional de Saneamento Básico: Perspectivas para as políticas e gestão dos serviços públicos. Brasília: Ministério das Cidades, 2009. vol. 2, p.271-294. 